\title{
Dopaminergic Modulation of Axon Collaterals Interconnecting Spiny Neurons of the Rat Striatum
}

\author{
Jaime N. Guzmán, ${ }^{1}$ Adán Hernández, ${ }^{2}$ Elvira Galarraga, ${ }^{1}$ Dagoberto Tapia, ${ }^{1}$ Antonio Laville, ${ }^{1}$ Ramiro Vergara, ${ }^{1}$ \\ Jorge Aceves, ${ }^{2}$ and José Bargas ${ }^{1}$ \\ ${ }^{1}$ Instituto de Fisiología Celular, Universidad Nacional Autonoma de Mexico, Mexico City DF 04510, Mexico, and 2Departamento de Fisiología, Centro de \\ Investigación y de Estudios Avanzados, Mexico City DF 07000, Mexico
}

\begin{abstract}
Dopamine is a critical modulator of striatal function; its absence produces Parkinson's disease. Most cellular actions of dopamine are still unknown. This work describes the presynaptic actions of dopaminergic receptor agonists on GABAergic transmission between neostriatal projection neurons. Axon collaterals interconnect projection neurons, the main axons of which project to other basal ganglia nuclei. Most if not all of these projecting axons pass through the globus pallidus. Thus, we lesioned the intrinsic neurons of the globus pallidus and stimulated neostriatal efferent axons antidromically with a bipolar electrode located in this nucleus. This maneuver revealed a bicuculline-sensitive synaptic current while recording in spiny cells. $\mathrm{D}_{1}$ receptor agonists facilitated whereas $\mathrm{D}_{2}$ receptor agonists depressed this synaptic current. In contrast, a bicuculline-sensitive synaptic current evoked by field stimulation inside the neostriatum was not consistently modulated, in agreement with previous studies. The data are discussed in light of the most recent experimental and modeling results. The conclusion was that inhibition of spiny cells by axon collaterals of other spiny cells is quantitatively important; however, to be functionally important, this inhibition might be conditioned to the synchronized firing of spiny neurons. Finally, dopamine exerts a potentially important role regulating the extent of lateral inhibition.
\end{abstract}

Key words: dopamine; neostriatum; basal ganglia; presynaptic modulation; lateral inhibition; GABA

\section{Introduction}

Activity of neostriatal projection neurons is controlled by inhibitory inputs (Aronin et al., 1986; Kita, 1993). Inhibition comes from two main sources: interneurons (Kita, 1993; Bennett and Bolam, 1994; Jaeger et al., 1994; Kawaguchi et al., 1995; Koos and Tepper, 1999) and recurrent axon collaterals interconnecting projection neurons (Park et al., 1980; Wilson and Groves, 1980; Somogyi et al., 1981; Bishop et al., 1982; Groves, 1983; Aronin et al., 1986; Bolam and Izzo, 1988; Czubayko and Plenz, 2002; Koos et al., 2002; Tunstall et al., 2002). We asked whether dopamine regulates the strength of synapses between projection neurons.

Synaptic terminals from spiny neurons are presynaptically modulated by dopamine at their target nuclei (e.g., pallidum and substantia nigra reticulata) (Floran et al., 1990, 1997; Radnikow and Misgeld, 1998; Cooper and Stanford, 2001). Consequently, our hypothesis was that the same type of regulation should be present within the neostriatum. To address this hypothesis, we examined synaptic inhibition between spiny neurons by activating axon collaterals antidromically from the pallidum (Park et al.,

\footnotetext{
Received March 21, 2003; revised Aug. 6, 2003; accepted Aug. 11, 2003.

This work was supported by the following grants: Dirección General de Asuntos del Personal AcadémicoUniversidad Nacional Autonoma de Mexico (UNAM) (Mexico) IN202300 (J.B.) and IN202100 (E.G.); Consejo Nacional de Ciencia y Tecnologia (Mexico) 31839-N (J.B.); and The Millenium Research Initiative W-8072/35806-N (J.B., E.G.). We thank M. C. Vilchis and the Microscopy Unit of Instituto de Fisiología Celular-UNAM for technical support. We also thank F. Tecuapetla for intensity-amplitude plots.

Correspondence should be addressed to José Bargas, Instituto de Fisiología Celular, Circuito exterior s/n (P.O. Box 70-253 for ordinary mail) Universidad Nacional Autonoma de Mexico, Mexico City DF 04510, Mexico. E-mail: jbargas@ifisiol.unam.mx.

Copyright $\odot 2003$ Society for Neuroscience $\quad$ 0270-6474/03/238931-10\$15.00/0
}

1980). The globus pallidus (GP) was first lesioned with ibotenic acid to destroy intrinsic pallidal cells. Related questions were whether modulation produced by $\mathrm{D}_{1}$ receptor agonists is different from, or even opposed to, that produced by $\mathrm{D}_{2}$ receptor agonists (Floran et al., 1990, 1997; Radnikow and Misgeld, 1998; Cooper and Stanford, 2001) and whether spiny neurons from the direct and the indirect pathways (Gerfen and Young, 1988; Albin et al., 1989) are synaptically interconnected (Aronin et al., 1986; Bolam and Izzo, 1988; Yung et al., 1996).

To observe whether there was a difference in the modulation of synaptic currents, recordings resulting from axon collaterals stimulation were compared with those evoked after intrastriatal field stimulation. The latter responses are likely to be variable because they come from a mixed source of GABAergic terminals: several classes of interneurons and recurrent axon collaterals (Kita, 1993; Jaeger et al., 1994; Kawaguchi et al., 1995; Koos and Tepper, 1999; Fitzpatrick et al., 2001). In case all interneuron types do not respond in the same manner to different classes of dopamine receptor agonists (Aosaki et al., 1998; Bracci et al., 2002; Centonze et al., 2002, 2003; Yasumoto et al., 2002; Gao et al., 2003), it is expected that variety will make this mixed source inconsistent when responding to the agonists. In contrast, if antidromic stimulation from the pallidum evokes IPSCs from a single source (i.e., axon collaterals), then the responses in this case are likely to be more consistent.

A dopaminergic modulation should be seen as consistent, however, even after intrastriatal field stimulation, if its presence is somehow ubiquitous or predominant (Pisani et al., 2000; Mo- 


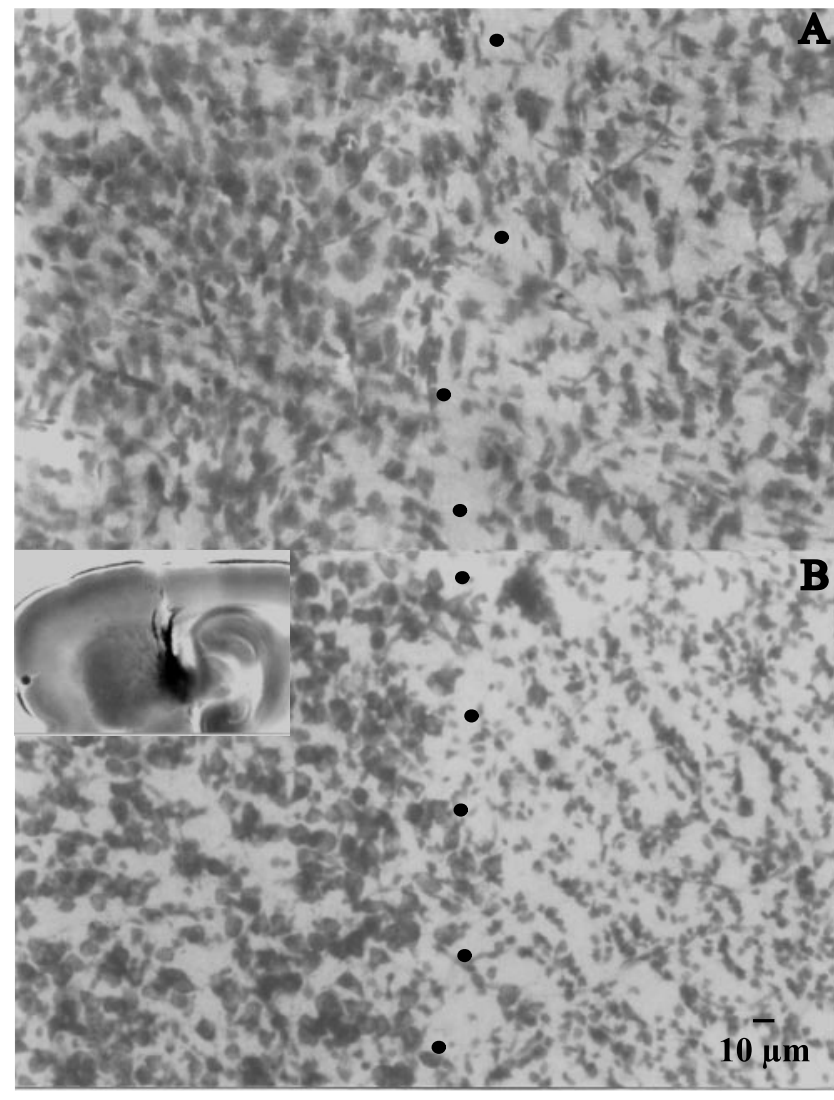

Figure 1. Pallidal lesions. $A, A 40 \mu \mathrm{m}$ histological section taken from a sagittal $300 \mu \mathrm{m}$ slice obtained from an animal perfused transcardially with saline containing choline instead of $\mathrm{Na}^{+}$ (see Materials and Methods). Dots approximately depict the border between pallidum (right) and neostriatum (left). B, A similar section taken from an ibotenic acid-lesioned animal. Notice a marked reduction in cellular profiles in the right side (pallidum). The inset shows the approximate trajectory of the lesioning needle when using the coordinates described in Materials and Methods. Injections were placed as far as possible from the striatopallidal border to avoid diffusion of ibotenic acid into the neostriatum. Methylene blue was used to stain the injection site. Histological sections were processed for Nissl staining.

miyama and Koga, 2001; Centonze et al., 2003). Otherwise, modulation would be concealed by the mixed source of differentially modulated inputs (Fitzpatrick et al., 2001). This work reports strong evidence of a selective role of dopamine in the presynaptic modulation of recurrent axon collaterals that interconnect spiny neurons.

Parts of this work have been reported previously in abstract form (Guzman et al., 2002).

\section{Materials and Methods}

Animals. Eighteen-day-old Wistar rats (27-28 gm) from our animal house were lesioned unilaterally in the GP with ibotenic acid (Fig. 1). Under sodium pentobarbital anesthesia ( $50 \mathrm{mg} / \mathrm{kg}$ ), animals were placed in a stereotaxic instrument (David Kopf, Carnegie Medicine, Stockholm, Sweden). Ibotenic acid solution (dissolved in PBS adjusted to $\mathrm{pH} 7.4$ with $\mathrm{NaOH})$ or the same volume $(3.0 \mu \mathrm{g} / 0.4 \mu \mathrm{l})$ of vehicle in the controls was injected into the GP using the stereotaxic coordinates: $1.5 \mathrm{~mm}$ posterior to bregma, $3.8 \mathrm{~mm}$ lateral to the midline, and $5.0 \mathrm{~mm}$ from the dural surface. These values follow the system of Paxinos and Watson (1982) to establish coordinates (i.e., referred to bregma), but they do not correspond to the values for adult animals (Fig. $1 B$, inset). Animals were anesthetized $1-2 \mathrm{~d}$ after the lesion and killed by decapitation. The $\mathrm{Na}-$ tional Institutes of Health publication, Principles of Laboratory Animal Care, was followed, and procedures were approved by the Animal Care Commission of the Instituto de Fisiología Celular.
Slice preparation and electrophysiology. Commonly, the brain was removed into ice-cold saline $\left(4^{\circ} \mathrm{C}\right)$ containing the following (in $\mathrm{mm}$ ): 123 $\mathrm{NaCl}, 3 \mathrm{KCl}, 1 \mathrm{MgCl}_{2}, 1 \mathrm{CaCl}_{2}, 25 \mathrm{NaHCO}_{3}$, and 11 glucose (pH 7.4 with $\mathrm{NaOH}, 298 \mathrm{mOsm} / \mathrm{l}$ with glucose; saturated with $95 \% \mathrm{CO}_{2}$ and $5 \% \mathrm{O}_{2}$ ). Choline-chloride and choline- $\mathrm{HCO}_{3}$ substituted for $\mathrm{NaCl}$ and $\mathrm{NaHCO}_{3}$, respectively, when preparation was used to record from pallidal neurons. In these latter cases, rats were perfused transcardially with choline-saline previously to better preserve pallidal cells (Fig. $1 \mathrm{~A}$, right). Parasagittal neostriatal slices ( $300 \mu \mathrm{m}$ thick) were cut in $4^{\circ} \mathrm{C}$ saline using a vibratome (Ted Pella, Reading, CA). Slices were then transferred to room temperature saline $\left(23-25^{\circ} \mathrm{C}\right)$ and allowed to recover for $1 \mathrm{hr}$. Thereafter, slices were transferred to a custom Plexiglas recording chamber and superfused continuously with oxygenated saline $(3-6 \mathrm{ml} / \mathrm{min}$; $\mathrm{Na}$-salts in all cases). Individual neurons were visualized $(40 \times$ water immersion objective) under differential interference contrast enhanced visual guidance using infrared videomicroscopy in an adapted upright microscope (Diaphot; Nikon, Melville, NY) with a camera (CCD-100; Dage-MTI, Michigan City, IN).

Micropipettes were made with borosilicate glass pulled in a FlamingBrown puller (Sutter Instruments, Novato, CA) fire polished for DC resistances of $\sim 3-6 \mathrm{M} \Omega$. Because some previous attempts to record inhibition between spiny neurons may have failed as a result of the small amplitude of the signal, our internal solution had a high $\mathrm{Cl}^{-}$concentration containing the following (in mM): $72 \mathrm{KH}_{2} \mathrm{PO}_{4}, 36 \mathrm{KCl}, 2 \mathrm{MgCl}_{2}, 10$ HEPES, 1.1 EGTA, 0.2 Na $\mathrm{NTP}_{2}$, $0.2 \mathrm{Na}_{3} \mathrm{GTP}, 5 \mathrm{QX}-314$, and $0.5 \%$ biocytin, pH 7.2, $275 \mathrm{mOsm} / \mathrm{l}$ (Koos et al., 2002). QX-314 was added to block both antidromic and orthodromic unclamped action currents that distorted evoked synaptic currents (see Fig. 2 A). A striatal field potential is shown in Figure $2 A 1$ to compare the latencies of its antidromic $\left(\mathrm{N}_{1}\right)$ and orthodromic $\left(\mathrm{N}_{2}\right)$ components with those obtained in the whole-cell configuration. A method to obtain population spikes in slices has been described previously (Bargas et al., 1998). Whole-cell recordings used standard techniques. Cells with zero current potential more negative than $-70 \mathrm{mV}$, input resistance $>200 \mathrm{M} \Omega$, and holding current (in voltage-clamp mode) $\leq 0.025 \mathrm{nA}$ to maintain a holding potential near the resting potential of the cell were chosen. Neostriatal cells were selected deeper than two cell layers below the surface of the slice. Wholecell recordings were made using an Axoclamp 2B amplifier (Axon Instruments, Foster City, CA). Whole-cell access resistances were in the range of 5-20 M $\Omega$. Access resistance was monitored continuously, and experiments were abandoned if changes $>20 \%$ were encountered. No cell capacitance, series resistance, or liquid junction potential $(2 \mathrm{mV})$ compensations were made.

Synaptic events were evoked with a bipolar concentric tungsten electrode ( $12 \mu \mathrm{m}$ at the tip; $50 \pm 8 \mathrm{k} \Omega \mathrm{DC}$ resistance) (FHC, Bowdoinham, $\mathrm{ME})$. Paired shock stimulation (45-50 msec of interstimulus interval; $0.2-0.4$ msec duration; $1-4 \mathrm{~V}$ delivered to the stimulating electrode at a frequency of $0.1 \mathrm{~Hz}$ ) was controlled with a computer interface (see below). Isolation units (Digitimer, Hertfordshire, UK) between the computer and the stimulating electrodes were used to quickly adjust stimulus parameters during the experiment. The stimulus strength was such that cortical stimulation did not evoke monosynaptic (charge spread) or polysynaptic (extensive striatal activation) IPSCs (see Fig. $3 A$ ) as tested in a sample of slices. The distance between recording and stimulating electrode in all configurations was $\sim 1 \mathrm{~mm}$. In theory, field stimulation can be adjusted to stimulate a single synaptic terminal (Hanse and Gustafsson, 2001), and the recruitment of a given number of terminals is proportional to stimulus strength (see Fig. 2C3); however, terminals recruited by field stimulation may belong to different axons. Terminals releasing during the first shock might be the ones with the higher probability of release, whereas those recruited with the second shock might be those that had a release probability that was enhanced by residual $\mathrm{Ca}^{2+}$ (Zucker, 1999). Stimulus strength cannot be raised without limit, because obvious damage to the tissue is evident at high intensities. In the present study, stimulus strength was maintained below the first local "ceiling" or saturation of the intensity-amplitude plot as shown in Figure $2 C 3(\sim 1-4 \mathrm{~V})$. Synaptic responses evoked with this stimulus strength were recognized by its having quantal variation (see Fig. 8), and in some cases, failures (data not shown), although we did not perform intensity- 
$\mathbf{A}$

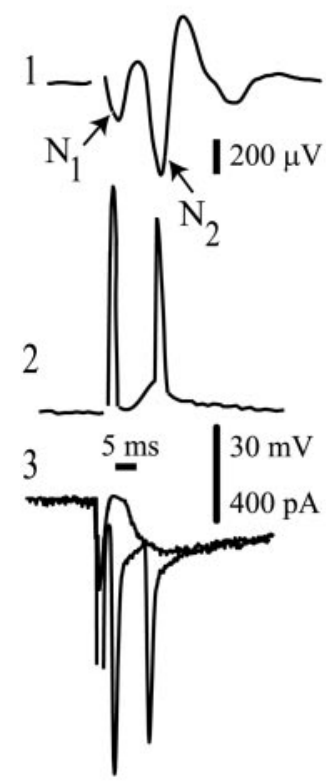

B

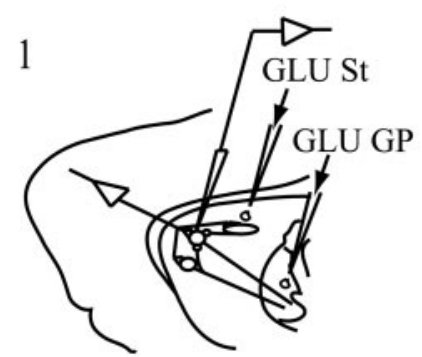

2

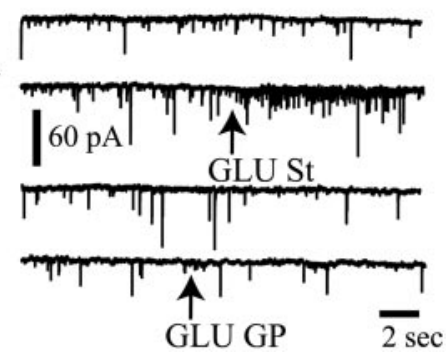

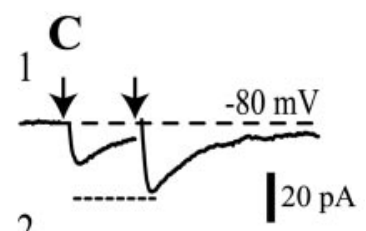

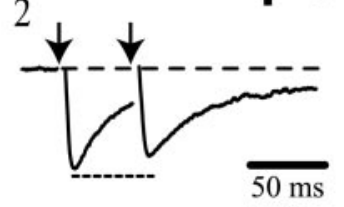

3

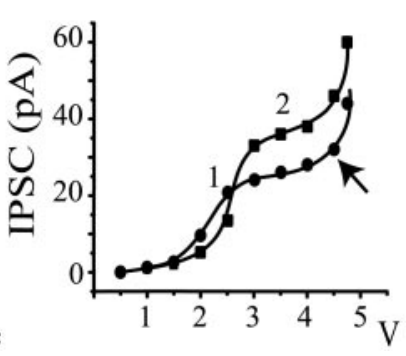

Figure 2. Orthodromic responses evoked antidromically. A, Top to bottom, Striatal population spike (1) voltage recording (2) and whole-cell currents ( 3 ) evoked during GP stimulation in the absence of CNQX or QX-314. B, The scheme depicts the experimental protocol to evoke synaptic activity with glutamate puffs (1). Synaptic activity is enhanced only after a glutamate puff in the neostriatum (arrows) (2). C, IPSCs evoked after antidromic stimulation of striatal axons in the GP. Weak stimulus strength produces paired-pulse facilitation (1), whereas stronger stimulus strength evokes paired-pulse depression (2). Twenty-five trials with failures were averaged for each trace. The intensity-amplitude relationship was plotted (3) for both first (filled circles) and second (filled squares) IPSCs. St, Striatum.

amplitude plots in each case. Unless stated otherwise, traces shown are the average of $\sim 2$ min recordings ( 10 traces) taken after the amplitude had been stabilized in a given condition. A small hyperpolarizing voltage command $(15 \mathrm{mV})$ was constantly given during the experiment to monitor input conductance. Changes in input conductance were detected in some cells during the addition of $\mathrm{D}_{1}$ receptor agonists (see Discussion).

The relative importance of pallidostriatal transmission on spiny cells was assessed by comparing the effects of glutamate applications on the synaptic activity of the recorded spiny cell. Choline-perfused unlesioned animals were used for this test. Thus, glutamate was added with pressure pulses or "puffs" (20 psi; $1 \mathrm{sec)}$ on either the pallidum or the striatum near $(1 \mathrm{~mm})$ the recorded neuron (see Fig. $2 B$ ) by means of a pneumatic drug ejection system, PDES-2L (npi Electronics, Tamme, Germany), connected with a low-resistance pipette $(0.2-0.5 \mathrm{M} \Omega)$ filled with bath saline and glutamate $(20 \mu \mathrm{M})$ placed $\sim 50 \mu \mathrm{M}$ under the slice surface.

All recordings were filtered at $1-3 \mathrm{kHz}$ and digitized with an AT-MIO16E10 (National Instruments, Austin, TX) DAQ (NI-DAQ) board in a PC clone. On-line data acquisition used custom programs made in the Labview environment (National Instruments). The NI-DAQ board was used to save the data on binary files in the computer hard disk for additional off-line analysis.

Data processing. Digitized data saved on disk were imported for analysis and graphing into commercial graphing software (Origin v. 6.; Microcal, Northampton, MA). IPSC amplitudes were measured from basal line to peak for the first response (IPSC1). For the second response (IPSC2), the basal line remaining from the first response was subtracted. Only IPSC1 was used to compare amplitudes before and during drug application. The paired-pulse ratio (PPR) was IPSC2 amplitude over IPSC1 amplitude. PPR in the control condition was a function of stimulus strength. Lower stimulus strength tended toward facilitation (when all traces including failures were averaged). In a certain range (1-4 V) controls could exhibit either depression or facilitation. Distribution-free statistical procedures (Systat v.7.; SPSS, Chicago, IL) were used to find data significance.

Pharmacology. Drugs were dissolved in the bath saline from stock solu- tions made daily using a gravity-driven superfusion system. Equilibrated concentrations of the drugs were achieved in 4-5 min. In this work, only one dopaminergic selective receptor agonist was used in the same preparation to avoid complex effects such as receptor cooperativity or interactions. All of the following were purchased from Sigma (St. Louis, MO): 6-cyano-2,3-dihydroxy7-nitro-quinoxaline disodium salt (CNQX), D-(-)-2-amino-5-phosphonovaleric acid (AP5), L-glutamic acid [glutamate (GLU)], SKF 81297, SCH 23390, bicuculline, QX-314, quinelorane, quinpirole, and sulpiride.

Immunohistochemistry. Neurons were filled with biocytin during recording. Slices with a single filled neuron were taken into consideration for immunocytochemistry. A combination of intracellular labeling and substance $\mathrm{P}$ (SP) or enkephalin (ENK, Leu, or Met) immunocytochemistry, but not both, was used to determine the peptide expressed in each recorded cell. Slices containing injected neurons were fixed overnight in $4 \%$ paraformaldehyde and $1 \%$ picric acid in $0.1 \mathrm{M}$ PBS, $\mathrm{pH}$ 7.4. The slices were then infiltrated with $30 \%$ sucrose and cut on a vibratome into $40 \mu \mathrm{m}$ sections. The sections were incubated $4-6 \mathrm{hr}$ in PBS solution containing 0.2 Triton X-100 and avidin conjugated to Texas Red (12.5 $\mu \mathrm{g} / \mathrm{ml}$; Vector Laboratories, Burlingame, CA) to label the recorded neuron.

Sections were then processed for conventional immunocytochemistry and fluorescence to demonstrate either SP or ENK using commercially available antisera (Peninsula Labs, San Carlos, CA) conjugated to fluorescein isothiocyanate. Slices were not processed for both antisera but one was chosen in each case. Thus, in each trial, either SP- or ENK-negative neurons could also be recorded. Therefore, our cell samples were divided into four pools with $p \approx 0.25$ of appearance: SP- and ENK-positive and SP- and ENK-negative, to report dopaminergic actions (see Results). Briefly, sections were rinsed in PBS and incubated for $18-24 \mathrm{hr}$ at $4^{\circ} \mathrm{C}$ with primary rabbit antibody against ENK or SP (diluted 1:200). After rinsing in PBS, sections were reincubated for $1 \mathrm{hr}$ with secondary antibodies conjugated to FITC (diluted 1:100). Sections were mounted in an anti-quenching media (Vectashield, Vector Laboratories) and examined under a confocal microscope (MRC1024; Bio-Rad, Natford, UK) equipped with a krypton-argon mixed-gas laser. Two laser lines emitting at 490 and $560 \mathrm{~nm}$ were used for exciting FITC and Texas Red, respectively. Immunostained cells were studied either on single confocal images or on reconstructed sections made by projecting z-series of three to four consecutive confocal images $10 \mu \mathrm{m}$ apart collected throughout the thickness of the section. The background noise was reduced averaging three to six images. Digitized images were transferred to a personal computer (Confocal Assistant, T. C. Brelje). Negative controls were to run an assay with excess SP or ENK (5 nM) mixed with primary antiserum, or omission of the primary antibodies, applying only the secondary antibody. Our goal was to immunoreact biocytin-filled neurons. In $\sim 50 \%$ of cases, the biocytin-filled neuron was negative (or positive) to the antiserum tested in the presence of neighboring positive and negative neurons.

\section{Results}

Synaptic currents from spiny axon collaterals can be isolated Figure $2 \mathrm{~A}$ illustrates responses of neostriatal neurons after field stimulation in the GP in the absence of any blocker. The striatal field potential (Fig. 2A1, population spike) recorded in these conditions exhibits $\mathrm{N}_{1}$ and $\mathrm{N}_{2}$ components. The $\mathrm{N}_{1}$ component is known to represent the population antidromic action potential, 
A
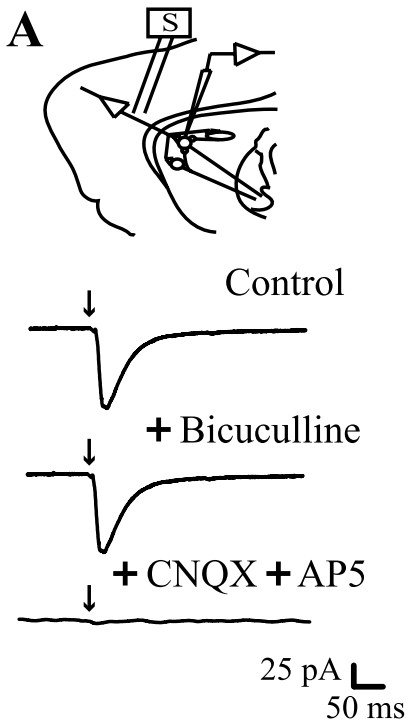

B
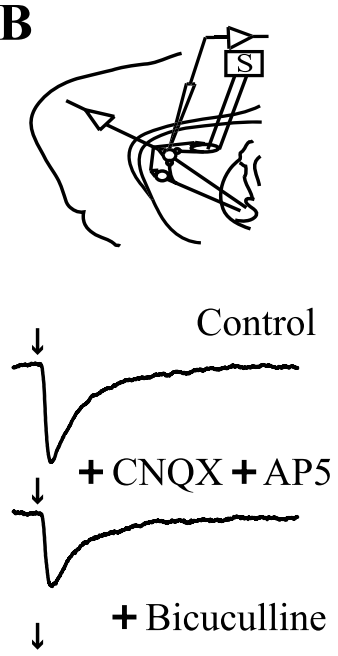
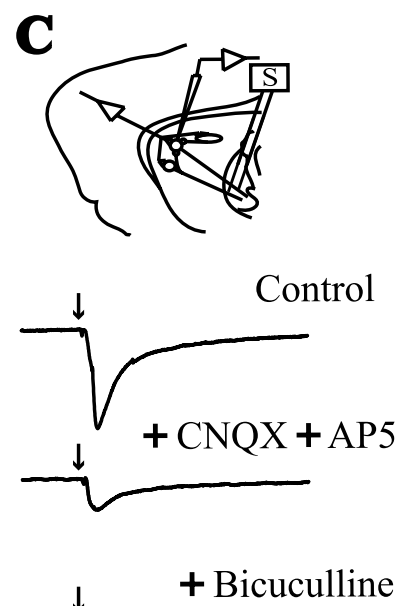
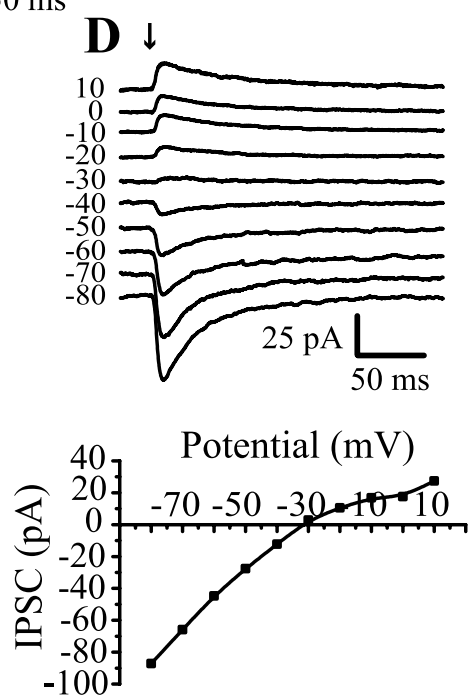

Figure 3. Evoked synaptic responses in a corticostriatal slice preparation. Top scheme in each frame illustrates the position of stimulating and recording electrodes; two medium spiny (round) and one local interneuron (ovoid) are symbolized. $A$, Synaptic currents were evoked by cortical stimulation (in this case, recordings are averages of 200 trials). Currents were blocked by CNQX (10 $\mu \mathrm{M})$ plus AP5 $(50 \mu \mathrm{M})$. No bicuculline-sensitive component was recorded with these stimulating conditions (1-4V) (see Materials and Methods). B, Stimulation and recording in the neostriatum evoked synaptic currents that were only partially blocked by glutamatergic antagonists (CNQX and AP5 as before). Bicuculline (10 $\mu \mathrm{m})$ blocked a GABAergic component. C, Stimulation in the GP (lesioned with ibotenic acid) and recording in the neostriatum. Axons from spiny cells were activated antidromically to turn on collaterals interconnecting spiny cells. Glutamatergic components (cortical projections also pass through GP) were blocked by CNQX plus AP5. A clear bicuculline-sensitive component was disclosed. D, Synaptic currents evoked by antidromic stimulation in the GP. Reversal potential was $-28.7 \pm 7 \mathrm{mV}(n=12)$, which was not significantly different from the chloride equilibrium potential $(-30.5 \mathrm{mV})$.

and it is $\sim 10-20 \%$ of the amplitude of the orthodromic component $\mathrm{N}_{2}$ (Bargas et al., 1998), meaning that in 1 of 10 neurons, an antidromic spike is evoked with this stimulation protocol. In fact, whole-cell recordings in both current-clamp (Fig. 2A2) and voltage-clamp modes (Fig. 2A3) show antidromic and orthodromic action potential-currents with similar latencies as the $\mathrm{N}_{1}$ and $\mathrm{N}_{2}$ components in a portion of cells $(n=2$ of 10$)$. Orthodromic spikes arise from underlying synaptic events. Figure $2 \mathrm{A3}$ illustrates a subthreshold synaptic event. An increase of stimulus strength produced the appearance of action currents. This shows

A
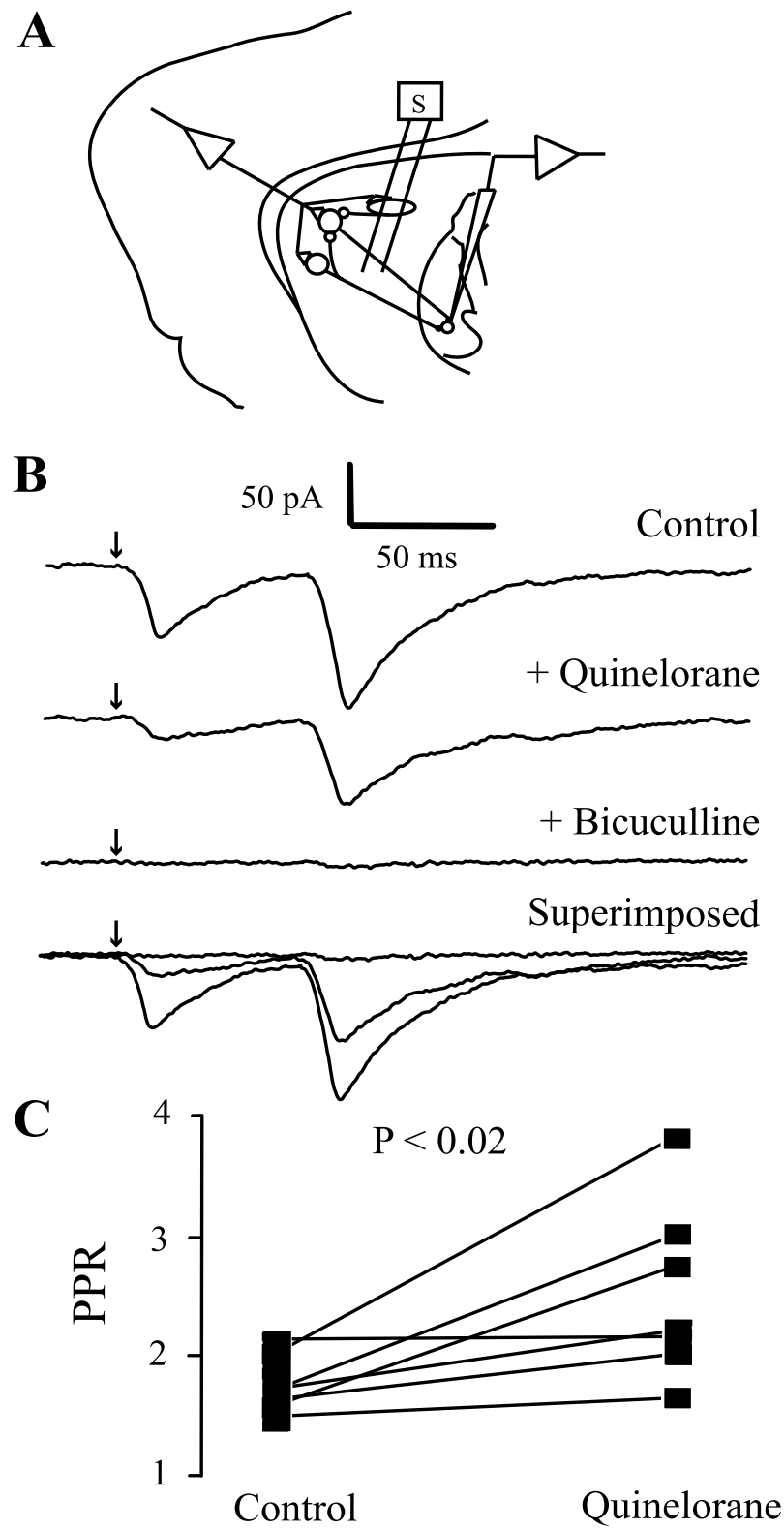

Figure 4. Dopaminergic modulation of striatopallidal transmission. $A$, Recording of pallidal neurons during striatal stimulation. $B$, Top to bottom, Control synaptic currents in the presence of CNQX (10 $\mu \mathrm{M})$ and AP5 $(50 \mu \mathrm{M})$. The action of quinelorane $(100 \mathrm{~nm})$ reduced synaptic currents and increased PPR in six of seven cells; bicuculline blocked all currents evoked from the striatum. The last trace superimposes all of the above records. C, Graph summarizing the results.

that striatopallidal axons can be stimulated antidromically from the GP.

Electrical stimulation, such as that used in Figure $2 \mathrm{~A}$, may activate both nearby axons (striatopallidal and cortical descending) and pallidal neurons. To test the possible participation of the pallidostriatal connection (Rajakumar et al., 1994; Bevan et al., 1998; Kita and Kita, 2001) in the responses of Figure $2 A$, we needed to stimulate pallidal somata without activating passing axons. Glutamate ionotropic receptors are located in the somatodendritic but not axonal membrane. Therefore, glutamate was administered by pressure (puff) with a micropipette located around the recorded neuron (1 mm) (Fig. 2B1, scheme) (see Materials and Methods). Synaptic activity was enhanced only after a glutamate puff in the neostriatum (Fig. 2 B2, arrows); however, it was not enhanced when glutamate was released on the GP 

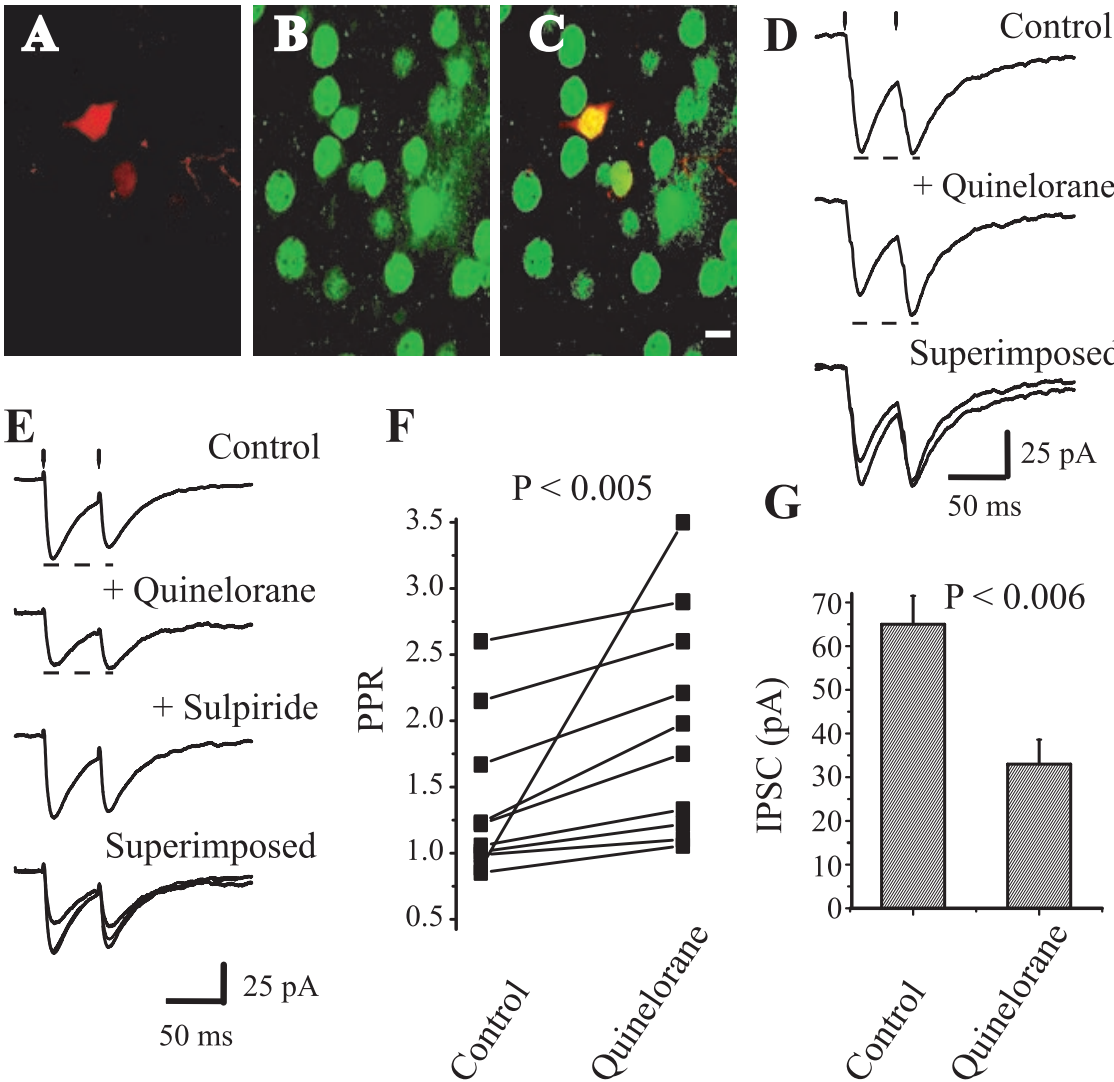

\section{G}

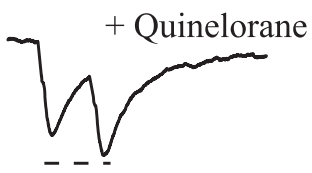

Superimposed
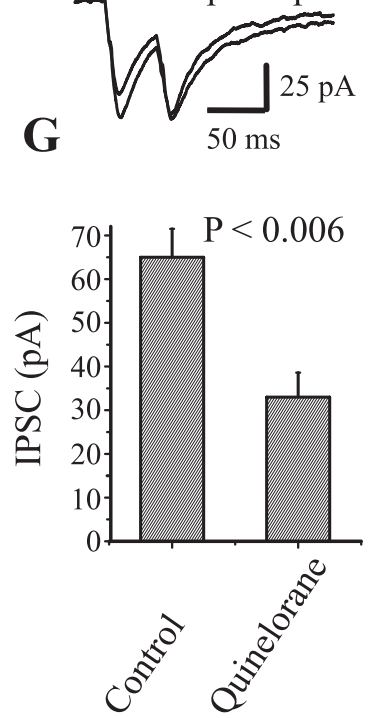

tensity-amplitude plot of antidromically evoked IPSCs is depicted in Figure 2C3. It has a sigmoidal shape with a local maximum (saturation) for both first (circles) and second (squares) IPSCs. Additional increases in stimulus strength may recruit more terminals (Fig. 2C3, arrow) and give a ladder-like appearance to the plot; however, we chose to limit stimulus strength to that which evokes responses equal to or below the local maximum, which may elicit facilitation (Figs. $2 C 1,5 D, 6 D$ ) or depression (Figs. 2C2, 5E, 6E) for the control pair. The amplitude of this first maximum could attain up to $250 \mathrm{pA}$ : range, $10-250$ pA $(n=6)$. In contrast, IPSCs evoked intrastriatally had a local maximum amplitude range of $20-500 \mathrm{pA}(n=11)$ (see below).

To assess the extent of charge diffusion with this stimulation strength $(\approx 1-4 \mathrm{~V})$, we recorded responses to cortical stimulation. It was seen that this stimulus strength did not activate GABAergic components in a neostriatal cell recorded $1 \mathrm{~mm}$ apart because evoked currents were unchanged by bicuculline ( $n=10)$ (Fig. $3 A$ ), but they were totally blocked by CNQX plus AP5. This result suggested that there was no charge diffusion from one nucleus to the other when the recorded cell and the stimulating electrode were $1 \mathrm{~mm}$ apart. Stronger stimulus strength might produce polysynaptic GABAergic components (data not shown).

The same range of stimulus strength and distance between recording and stimulating electrodes was used to stimulate intrastriatally (Fig. 3B). In this case, CNQX plus AP5 failed to block all evoked

$(n=6)$. This result suggests that pallidostriatal input on spiny cells is mild. Despite this result, the GP was lesioned in the present work (see Materials and Methods) because of a possible selective pallidostriatal input to some spiny neurons.

The efferent axons of all neostriatal projection neurons pass through and project to the GP (Bishop et al., 1982; Kawaguchi et al., 1990). Results illustrated in Figure 2, $A$ and $B$, suggested that inhibition from medium spiny neurons could be recorded, in medium spiny neurons, without important pallidostriatal contamination if antidromic stimulation of striatal axons was given in the GP. Figure $2 C$ illustrates a representative test of this inference: paired-pulse synaptic responses evoked by antidromic GP stimulation in the presence of the glutamate ionotropic receptor antagonists CNQX $(10 \mu \mathrm{M})$ and AP5 $(50 \mu \mathrm{M})$. This maneuver blocked excitatory responses evoked by stimulating descending cortical fibers antidromically. In addition, QX-314 (5 mM) was used in the recording pipette to block antidromic or orthodromic action currents such as those recorded in Figure $2 \mathrm{~A}$ (see Materials and Methods). These two maneuvers isolated IPSCs evoked by antidromic stimulation of striatal axons in the GP (Fig. 2C). Weaker stimulus strengths had more probability to elicit pairedpulse facilitation (Fig. 2C1), whereas stronger stimulus always elicited paired-pulse depression (Fig. 2C2). A representative in- current, and a bicuculline-sensitive $(5 \mu \mathrm{M})$ synaptic component was always recorded. It has been suggested that this IPSC is mostly attributable to the activation of GABAergic interneurons (Kita, 1993; Jaeger et al., 1994; Kawaguchi et al., 1995).

Figure $3 C$ shows that synaptic responses evoked by antidromic stimulation from the GP also have a bicuculline-sensitive component, although somewhat smaller than that evoked intrastriatally with similar stimulation parameters (amplitudes mean \pm SEM $): 67 \pm 4.5 \mathrm{pA}(n=26)$ versus $93 \pm 7.1 \mathrm{pA}(n=17)$, respectively ( $p<0.005$; Mann-Whitney $U$ test). The reversal potential of these IPSCs was $-28 \pm 7 \mathrm{mV}(n=12)$ (Fig. $3 D)$ $\left(\mathrm{E}_{\mathrm{Cl}}=-30.5 \mathrm{mV}\right)$ (see Materials and Methods).

\section{Probing dopaminergic receptor agonists with the paired-pulse paradigm}

When stimulating in the neostriatum and recording in pallidal cells, $100 \mathrm{nM}$ quinelorane reduced the synaptic responses from $172 \pm 42$ to $84 \pm 38 \mathrm{pA}(n=7 ; p<0.02$; Wilcoxon's $T$ test $)$ (Fig. $4 B)$. PPR increased from $1.7 \pm 0.8$ in the control to $2.5 \pm 0.3$ during quinelorane ( $p<0.02$; Wilcoxon's $T$ test). Quinpirole had the same effects $(n=3)$. Figure $4 C$ illustrates a summary of PPR change in a sample of experiments. 
Presynaptic modulation of axon collaterals by the activation of dopaminergic receptors

Figure $5 \mathrm{~A}$ shows a recorded neostriatal neuron filled with biocytin (Texas Red immunofluorescence). Figure $5 B$ shows the same field immunoreacted against substance P. SP-positive neurons were always surrounded by SP-negative ones. Figure $5 C$ shows previous figures superimposed. The recorded cell was clearly immunolabeled for SP (double labeling) and exhibited $\mathrm{D}_{2}$-mediated presynaptic inhibition of axon collaterals, as shown in Figure $5 D$. Two other SP-positive cells expressed $\mathrm{D}_{2}$ modulation, whereas four SP-positive cells expressed $\mathrm{D}_{1}$ modulation (see below); however, we did not test the same section with both SP and ENK antisera. This yielded negative cells. SP-negative cells had either $\mathrm{D}_{2}(n=3)$ or $\mathrm{D}_{1}(n=3)$ modulation when tested. Figure $5 D$ (top) shows a pair of evoked IPCSs recorded in the spiny neuron, as indicated in Figures $2 C$ and $3 C$ (antidromic GP stimulation). Quinelorane (100 nM) reduced the first response; however, PPR was increased (middle). Superimposed traces are shown at the bottom. It is possible to see a representative time course of this effect (see Fig. $8 A$ ). Quinelorane effects were blocked by sulpiride (Fig. 5E), showing reversibility and specificity for $\mathrm{D}_{2}$-mediated modulation. Mean PPR increased in a sample of neurons from $1.15 \pm 0.1$ to $1.52 \pm 0.17$ during quinelorane $(p<0.005 ; n=10$; Wilcoxon's $T$ test) (Fig. $5 F$ ). Mean IPSC amplitude was reduced from $65 \pm 6.5$ to $33 \pm 5.6 \mathrm{pA}(p<0.006$; Wilcoxon's $T$ test $)$

(Fig. 5G). Quinpirole had the same actions $(n=3)$. These results demonstrate dopaminergic $\mathrm{D}_{2}$-mediated modulation of recurrent axon collaterals of spiny neurons.

Figure $6 \mathrm{~A}$ shows a neostriatal neuron filled with biocytin, whereas Figure $6 B$ shows the same field immunoreacted against enkephalins. Figure $6 C$ shows superimposition of $A$ and $B$. The recorded cell was immunolabeled for ENK (double labeling). This and three other ENK-positive cells exhibited $D_{1}$-mediated presynaptic potentiation of axon collaterals, whereas four other cells exhibited $\mathrm{D}_{2}$ modulation. Six ENK-negative cells had $\mathrm{D}_{2}$ $(n=4)$ or $\mathrm{D}_{1}(n=2)$ modulation. Figure $6 \mathrm{D}$ shows that first, evoked IPSC was potentiated during $100 \mathrm{nM}$ SKF 81297 ( $n=12$ of 16), a selective $D_{1}$ receptor agonist. The second synaptic event was almost always reduced, and therefore PPR was decreased $(n=14$ of 16$)$ from $1.3 \pm 0.13$ to $0.9 \pm 0.08$ during SKF 81297 ( $n=16 ; p<0.0005$; Wilcoxon's $T$ test) (Fig. $6 F) . \mathrm{D}_{1}$ receptor activation was blocked by the selective $D_{1}$ receptor antagonist SCH 23390 (200 nM) (Fig. 6E). IPSC amplitude of the first response exhibited a tendency toward significant change from $68 \pm$ 6.2 to $86 \pm 9.2 \mathrm{pA}(n=16 ; p<0.09$ for Wilcoxon's $T$ test, but $p<$ 0.02 for the Student's $t$ test) (Figure $6 G$ ), despite a reduction of IPSC amplitude in some cells ( $n=3$ of 16 cells), probably resulting from a postsynaptic change caused by the $D_{1}$ agonist (Pacheco-Cano et al., 1996). These experiments show that PPR is
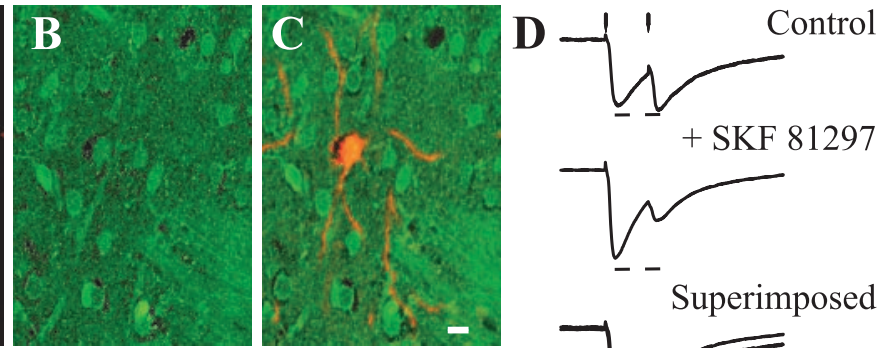

Superimposed

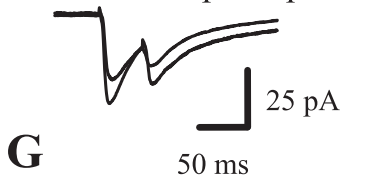

$\mathbf{F}$
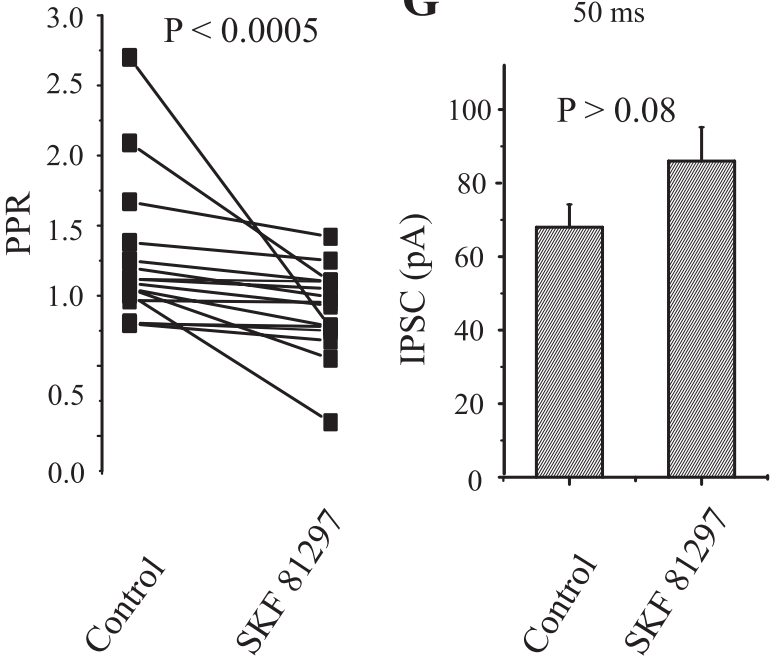

1.

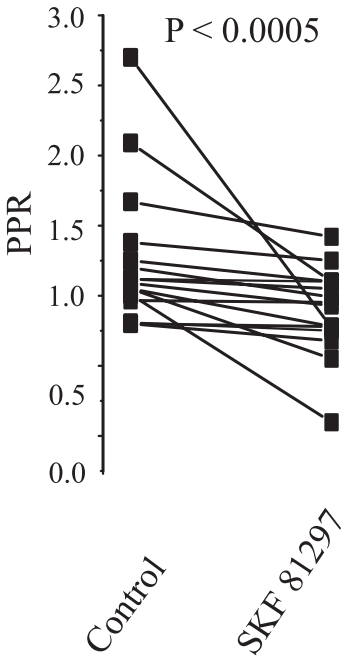

Figure 6. Dopaminergic modulation of medium spiny axon collaterals. Activation of $D_{1}$ receptors. Stimulating and recording electrodes as in Figure 1C. $A$, Neostriatal neuron filled with biocytin. $B$, Same preparation showing neurons immunoreactive fo ( Paired line graph illustrates PPR reductions in a sample of spiny neurons ( $p<0.0005 ; n=16)$. $G$, Using the same stimulus strength, the mean of IPSC amplitudes (first response of the pair) before and during SKF 81297.

a more reliable test than IPSC amplitude. We illustrated the time course of one of these cases (see Fig. $8 \mathrm{~B}$ ). These results demonstrate $\mathrm{D}_{1}$-mediated modulation of recurrent axon collaterals in spiny cells.

\section{Actions of dopaminergic receptor agonists on synaptic} responses evoked with intrastriatal field stimulation

Figure 7 illustrates the actions of dopaminergic receptor agonists on IPSCs elicited by stimulation within the neostriatum (Fig. 3B). Quinelorane (100 nM), in the presence of CNQX and AP5, modified significantly neither IPSC amplitudes nor the PPR in most (70\%) cells (Fig. 7A). The time course of a representative case is illustrated in Figure $8 C$. PPR changes were inconsistent from mean $1.4 \pm 0.07$ to $1.34 \pm 0.12$ during quinelorane $(n=7 ; p>$ 0.4; Wilcoxon's $T$ test) (Fig. $7 B$; compare with Figs. $5 F$ and $6 F$ ). Average IPSC amplitude was unchanged (Fig. 7C).

Figure $7 D$ illustrates a typical case for $\mathrm{D}_{1}$ action (100 nM SKF 81297). Bicuculline-sensitive currents, evoked intrastriatally, were significantly reduced by the $\mathrm{D}_{1}$ agonist $(p<0.01)$ (Fig. $7 F$ ) (Flores-Hernández et al., 2000; Gao et al., 2003). In some cases IPSC amplitude did not change, as seen in the time course of Figure $8 D$. This is opposite from the findings after antidromic GP stimulation. PPR did not change consistently or significantly when all cases were taken together: mean $1.3 \pm 0.16$ in controls 


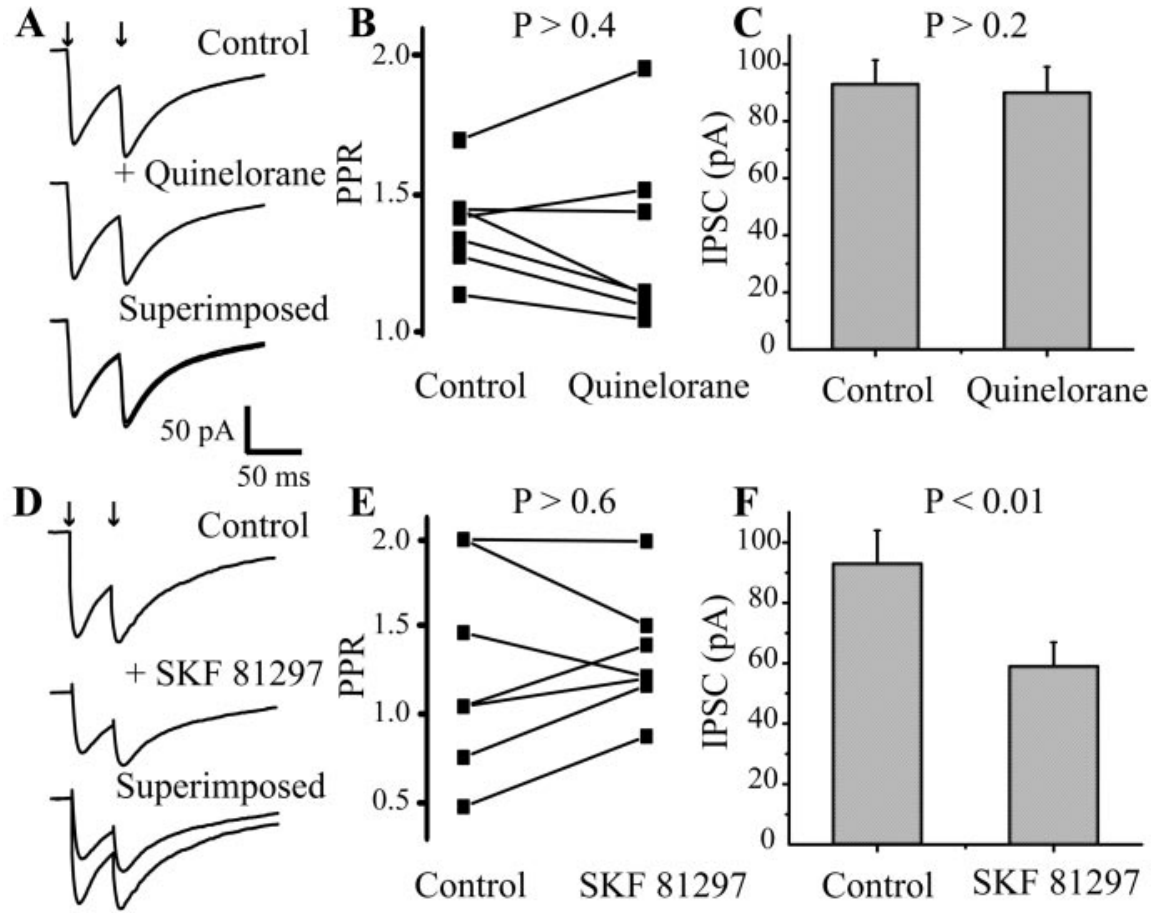

Figure 7. Lack of consistent dopaminergic modulation of synaptic currents evoked with intrastriatal field stimulation. Stimulating and recording electrodes as in Figure $1 B$. A, Quinelorane (100 nm) does not consistently change IPSC amplitude or PPR. $B$, Paired line graph shows an inconsistent pattern of PPR change. No more than one-third of cases exhibited a PPR increase $(p>0.4)$; some showed a decrease. C, When evoked intrastriatally, mean IPSC amplitude did not change during D agonist ( $p>0.2)$. D, SKF 81297 (100 nm) does not consistently change PPR. In the case shown, IPSC was reduced (in contrast to GP antidromic stimulation). $E$, Paired line graph shows an irregular pattern of PPR change ( $p>0.6$ ). $F$, Intrastriatally evoked mean IPSC exhibited a striking contrast with antidromically evoked mean IPSC; its average amplitude is reduced instead of enhanced $(p<0.01)$.

versus $1.3 \pm 0.1$ during $\mathrm{D}_{1}$ agonist $(n=10 ; p>0.6$; Wilcoxon's $T$ test) (Fig. $5 E$ ). These results reinforce the view that the two different sites of stimulation (neostriatum and GP) evoke synaptic responses from different sets of terminals.

\section{Discussion}

Measurement of PPR has proven to be a reliable method for studying presynaptic modulation (Dunwiddie and Haas, 1985; Kamiya and Zucker, 1994; Zucker, 1999; Barral et al., 2001; Cooper and Stanford, 2001; Gerdeman et al., 2002). With this method, a presynaptic $\mathrm{D}_{2}$-mediated modulation similar to that shown on the striatopallidal pathway (Cooper and Stanford, 2001; Mengual and Pickel, 2002) or in the cholinergic or fastspiking (FS) interneurons (Pisani et al., 2000; Momiyama and Koga, 2001; Centonze et al., 2003) was shown. Similarly, a presynaptic modulation by $\mathrm{D}_{1}$ receptor agonists as that reported in the striatonigral pathway (Floran et al., 1990, 1997; Cameron and Williams, 1993; Radnikow and Misgeld, 1998) was also shown, despite postsynaptic dopaminergic actions (Pacheco-Cano et al., 1996) on the subthreshold inward rectification (Galarraga et al., 1994; Nisenbaum and Wilson, 1995; Mermelstein et al., 1998; Farries and Perkel, 2000) that shunts inhibitory inputs (Fitzpatrick et al., 2001).

To summarize, $\mathrm{D}_{1}$ receptor agonists increase whereas $\mathrm{D}_{2}$ receptor agonists decrease GABAergic transmission between spiny cells.

\section{IPSCs from axon collaterals}

Amplitude dissimilarities of unitary IPSCs reported previously (current clamp) were probably attributable to differences in neu- ronal input impedance and somatic shunt. Thus, IPSCs of microvolts or millivolts can be measured when comparing intracellular (Tunstall et al., 2002) with whole-cell (Czubayko and Plenz, 2002) recordings, in both adult and young spiny cells. In voltage-clamp mode, unitary IPSCs range from 20 to 250 pA (Koos et al., 2002); the minimum is in the range of quantal events in other synapses (Hanse and Gustafsson, 2001). With our stimulation parameters, the average synaptic current, 67 pA (10$250 \mathrm{pA}$ ), was in the unitary range. Therefore, an average of five boutons per connection is a reasonable number (quantum, 10-20 pA, depending on intracellular $\left.\mathrm{Cs}^{+}\right)$. Similar stimulation parameters yielded an average IPSC of 93 pA (20-500 pA) for intrastriatal inhibition, suggesting that axon collateral inhibition is quantitatively less than interneuron inhibition; however, a spiny neuron receives $\sim 10,000$ asymmetrical (Kincaid et al., 1998) and $\sim 2500$ symmetrical synapses (Ingham et al., 1998). Symmetrical synapses can be dopaminergic, cholinergic, or GABAergic, with dopaminergic being $\sim 13 \%$ (Roberts et al., 2002). Assuming that cholinergic inputs are a similar percentage, 650 symmetrical synapses per spiny cell are not GABAergic. This leaves 1850 GABAergic synapses per spiny cell. How many come from axon collaterals? There are $\sim 2840$ striatal neurons inside the volume of a spiny dendritic tree (Oorschot, 1996; Kincaid et al., 1998). Most spiny neurons have their axon collaterals restricted to this volume (Kawaguchi et al., 1990). If 95\% of the neurons are spiny, the number of potentially contacting neurons onto a single centered spiny cell is $\sim 2700$. Only $\sim 10 \%$ of neighboring spiny neurons are connected with one another (Czubayko and Plenz, 2002; Tunstall et al., 2002); therefore, connecting spiny neurons total only $\sim 270$. An average of five contacts yields 1350 inhibitory synapses per spiny cell arising from axon collaterals: two-thirds of the GABAergic inputs. A similar calculation for interneurons explains the remaining contacts: $5 \%$ of the surrounding 2840 striatal neurons are interneurons, which is $\sim 140$. One-fourth of the surrounding spiny cells receive inputs from a centered interneuron (Koos and Tepper, 1999), which leaves $\sim 30$ interneurons converging in a single spiny cell. Fast- and low-threshold spiking interneurons might leave up to 15 (range, 8-15) contacts per spiny cell (Kubota and Kawaguchi, 2000). Thus, $30 \times 15=500$ contacts from interneurons. The later calculation has experimental support: 4-27 FS interneurons may converge on a single projection cell (Koos and Tepper, 1999). This makes an average of 16 interneurons of a single class converging on a spiny cell, which makes $16 \times 15=240$ contacts from one class of interneuron. Assuming the same number of contacts from both GABAergic interneuron genres (Kubota and Kawaguchi, 2000), the number of interneuronal contacts is again $\sim 500$. Thus, $70 \%$ of all GABAergic contacts are from axon collaterals, and 30\% are from interneurons. These calculations are subject to error (e.g., various interneurons may be as complex as in the cortex), but assuming, provisionally, that these percentages may be correct, there is need 

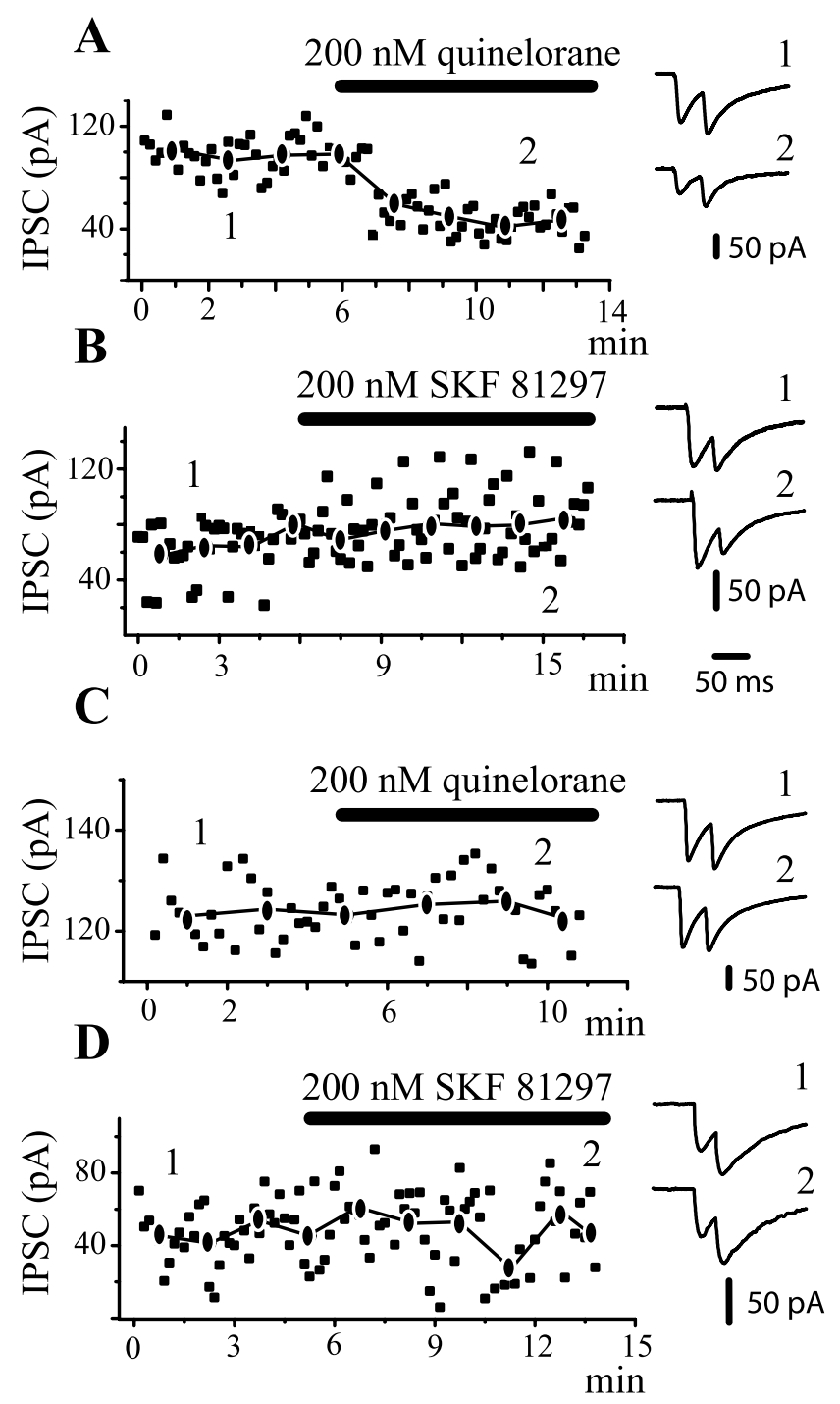

Figure 8. Time course of action of dopaminergic drugs. IPSCs exhibited amplitude variation from trial to trial, suggesting that only a few terminals were being activated. Amplitudes in each trial and mean amplitude of first IPSC were graphed in all cases $(A-D)$. A, IPSCs were evoked with antidromic stimulation from the GP, thus favoring activation of terminals from recurrent axon collaterals (as in Fig. 1C). After several minutes of control recordings, $200 \mathrm{~nm}$ quinelorane (dopaminergic $\mathrm{D}_{2}$ receptor agonist) was added to the superfusion. Quinelorane reduced IPSC amplitude and produced paired-pulse facilitation (PPR $>1$ ). Recordings at right, in this and the other frames, were taken before and during drug application, as indicated by the numbers. $B$, Same experimental arrangement as in $A$, except that $200 \mathrm{~nm}$ SKF 81297 (dopaminergic $D_{1}$ receptor agonist) was administered. A tendency to exhibit larger IPSC amplitudes is accompanied with paired-pulse depression (PPR $<1$ ). C, IPSCs are now intrastriatally evoked (as in Fig. 1B). Quinelorane produced neither amplitude nor PPR changes in most cases. D, Same experimental arrangement as in C, except that SKF 81297 is administered. In this case, there was no consistent change of either mean amplitude or PPR. In several cases, the IPSC was reduced. Stimulus frequency was $0.2 \mathrm{~Hz}$. The traces at right are averages of 2 min recordings at approximate times indicated by the numbers.

to explain why the IPSC that is evoked intrastriatally is larger and why it responds inconsistently to dopaminergic receptor agonists.

First, the distance chosen between stimulating and recording electrodes $(1 \mathrm{~mm})$ very probably decreased the probability of stimulating axon collaterals connected to the recorded cell (Czubayko and Plenz, 2002; Tunstall et al., 2002). Second, field stimulation activates nearby axons. All other things being equal, the most potent inhibition will come from axons that possess the largest number of synchronously releasing contacts. Moreover, interneurons are prone to fire repetitively and tend to synchronize one another through gap junctions (Koos and Tepper, 1999), and each terminal bouton tends to have more than one active zone (Bevan et al., 1998). In addition, the FS interneurons preferentially target the perisomatic region and not only the dendrites of projection cells (Bennett and Bolam, 1994; Koos and Tepper, 1999; Kubota and Kawaguchi, 2000). Therefore, a striatal field stimulus will be biased toward interneurons and a larger IPSC (Jaeger et al., 1994). In support of this inference, large amplitude events (which need a number of synchronous boutons) interspersed with small ones can be recorded during spontaneous synaptic activity (Fig. 2B2). Furthermore, 4-aminopyridine reveals two types of inhibition in the neostriatum: one asynchronous with small IPSPs and the other, rhythmic, exhibiting barrages of large amplitude IPSPs, which persist in the presence of CNQX plus AP5 (Flores-Hernández et al., 1994).

The conclusion is that field stimulation inside the neostriatum activates a mixed source of GABAergic terminals favoring the terminals from interneurons. A lack of consistency in the action of dopaminergic drugs on intrastriatally evoked inhibition, as recorded in spiny cells, has been reported previously (Delgado et al., 2000; Fitzpatrick et al., 2001) and probably results from a great variety of dopaminergic actions on a diverse array of GABAergic terminals and interneurons targeting spiny cells (Lenz et al., 1994; Pisani et al., 2000; Momiyama and Koga, 2001; Bracci et al., 2002; Yasumoto et al., 2002; Centonze et al., 2003; Gao et al., 2003). When none of these actions predominate over the others in most trials, inconsistent effects should be seen.

In contrast, antidromic stimulation from the GP may isolate IPSCs from collaterals (Park et al., 1980; Katayama et al., 1981; Czubayko and Plenz, 2002; Koos et al., 2002; Tunstall et al., 2002). If that were true, a consistent dopaminergic modulation should be seen, which was the case, resulting in the initial description of this modulation. In addition, neostriatal projection neurons express $\mathrm{D}_{1}$ or $\mathrm{D}_{2}$ receptors (Surmeier et al., 1993; Hernandez-Lopez et al., 1997, 2000; Aizman et al., 2000), and consistent presynaptic actions as the result of the activation of these receptors have been reported at the target nuclei (Floran et al., 1990, 1997; Cameron and Williams, 1993; Radnikow and Misgeld, 1998; Cooper and Stanford, 2001). Moreover, $D_{1}$ postsynaptic actions are facilitatory (Hernandez-Lopez et al., 1997), whereas $D_{2}$ postsynaptic actions depress firing (Hernandez-Lopez et al., 2000) in spiny neurons. Such actions are consistent with what was found at the terminals of axon collaterals.

The GP was lesioned with ibotenic acid to minimize contamination from pallidostriatal fibers (Kuo and Chang, 1992; Bevan et al., 1998). This contamination should be small, because local stimulation of pallidal neurons with glutamate showed little effect on spiny neurons. Pallidal neurons are much less than neostriatal neurons (Oorschot, 1996), and only one-fourth of them innervate the neostriatum (Bevan et al., 1998; Kita and Kita, 2001): 1 of 240 spiny cells (Oorschot, 1996; Bevan et al., 1998). There are 800 intrastriatal boutons for each pallidal cell. More than half of them (up to 80\%) innervate interneurons (Bevan et al., 1998; Kita and Kita, 2001). Assuming that half of them (400) innervate spiny cells $\left[4.6 \times 10^{6}\right.$ boutons; $2.6 \times 10^{6}$ spiny cells (Oorschot, 1996)], the result is 2 boutons per spiny cell. Therefore, the probability of activating pallidostriatal terminals on spiny neurons instead of axon collaterals is low; however, a selective pallidostriatal innervation to certain spiny cells cannot be discarded. 
Which is the predominant inhibition? When a class of interneurons is stimulated, the number of activated terminals (Kubota and Kawaguchi, 2000) will make a potent inhibition (Koos and Tepper, 1999). On the other hand, if a large group of spiny cells has a physiological way to be turned on synchronously, the inhibition of axon collaterals will become relevant. This may occur during certain net states such as the up and down form of voltage oscillations (Stern et al., 1998). Thus, the predominant inhibition may be conditioned by the state of the net (such as when comparing climbing vs parallel inputs on Purkinje cells).

Although the effects of dopamine agonists on intrastriatally evoked IPSCs are inconsistent in the present sample, cases of clear modulation can be separated (Delgado et al., 2000), and they may come from either axon collaterals or interneurons (Aosaki et al., 1998; Centonze et al., 2003). On the other hand, although PPR did not change consistently during $\mathrm{D}_{1}$ receptor agonists, a significant and consistent decrease in IPSCs amplitude was seen, suggesting a mixture of postsynaptic (Flores-Hernández et al., 2000) and presynaptic (Centonze et al., 2003; Gao et al., 2003) $\mathrm{D}_{1}$ effects. This latter effect is the opposite of that found on IPSCs from axon collaterals and striatonigral terminals (Radnikow and Misgeld, 1998), demonstrating that the same modulator may have opposite actions on different GABAergic connections and neurons.

\section{Dopaminergic modulation of recurrent inhibition}

$\mathrm{D}_{1}$ receptor agonists increase (Radnikow and Misgeld, 1998) whereas $\mathrm{D}_{2}$ receptor agonists decrease (Cooper and Stanford, 2001) GABAergic transmission between spiny cells. $D_{1}$ and $D_{2}$ agonists were effective at nanomolar concentrations, and their actions were blocked by their respective antagonists. Combined, the data demonstrate that terminals in charge of lateral inhibition express dopaminergic receptors and may be modulated by dopamine. This is supported by a recent preliminary report using pair recordings with high intracellular chloride to enhance unitary IPSCs (Koos et al., 2002), as well as by other indirect studies (Rebec and Curtis, 1988). It was shown that neurons immunoreactive for SP and ENK received GABAergic synapses modulated by either $D_{1}$ or $D_{2}$ receptor agonists, suggesting that pathways containing one or both receptor types (Gerfen et al., 1990; Gerfen, 2000) communicate with one another (Aronin et al., 1986; Bolam and Izzo, 1988; Gerfen and Young, 1988; Yung et al., 1996).

\section{Physiological relevance}

Lateral inhibition is a mechanism used to explain basal ganglia function (Groves, 1983; Wickens, 1993), because it might generate a type of neuronal competition (Wickens, 1993; Wickens and Oorshcot, 2000) to filter, choose, or switch motor programs (Redgrave et al., 1999; Bar-Gad and Bergman, 2001) and contribute to establish working memory traces (Beiser and Houk, 1998). The present experimental work shows that lateral inhibition may be modulated by dopamine.

\section{References}

Aizman O, Brismar H, Uhlen P, Zettergren E, Levey AI, Forssberg H, Greengard P, Aperia A (2000) Anatomical and physiological evidence for D1 and D2 dopamine receptor colocalization in neostriatal neurons. Nat Neurosci 3:226-230.

Albin RL, Young AB, Penney JB (1989) The functional anatomy of basal ganglia disorders. Trends Neurosci 12:366-375.

Aosaki T, Kiuchi K, Kawaguchi Y (1998) Dopamine D1-like receptor activation excites rat striatal large aspiny neurons in vitro. J Neurosci 18:5180-5190.
Aronin N, Chase K, DiFiglia M (1986) Glutamic acid decarboxylase and enkephalin immunoreactive axon terminals in the rat neostriatum synapse with striatonigral neurons. Brain Res 365:151-158.

Bar-Gad I, Bergman H (2001) Stepping out of the box: information processing in the neural networks of the basal ganglia. Curr Opin Neurobiol 11:689-695.

Bargas J, Ayala GX, Hernandez E, Galarraga E (1998) $\mathrm{Ca}^{2+}$-channels involved in neostriatal glutamatergic transmission. Brain Res Bull 45:521-524.

Barral J, Poblette F, Mendoza E, Pineda JC, Galarraga E, Bargas J (2001) High-affinity inhibition of glutamate release from corticostriatal synapses by omega-agatoxin TK. Eur J Pharmacol 430:167-173.

Beiser DG, Houk JC (1998) Model of cortical-basal ganglionic processing: encoding the serial order of sensory events. J Neurophysiol 79:3168-3188.

Bennett BD, Bolam JP (1994) Synaptic input and output of parvalbuminimmunoreactive neurons in the neostriatum of the rat. Neuroscience 62:707-719.

Bevan MD, Booth PA, Eaton SA, Bolam JP (1998) Selective innervation of neostriatal interneurons by a subclass of neuron in the globus pallidus of the rat. J Neurosci 18:9438-9452.

Bishop GA, Chang HT, Kitai ST (1982) Morphological and physiological properties of neostriatal neurons: an intracellular horseradish peroxidase study in the rat. Neuroscience 7:179-191.

Bolam JP, Izzo PN (1988) The postsynaptic targets of substance $\mathrm{P}$-immunoreactive terminals in the rat neostriatum with particular reference to identified spiny striatonigral neurons. Exp Brain Res 70:361-377.

Bracci E, Centonze D, Bernardi G, Calabresi P (2002) Dopamine excites fast-spiking interneurons in the striatum. J Neurophysiol 87:2190-2194.

Cameron DL, Williams JT (1993) Dopamine $\mathrm{D}_{1}$ receptors facilitate transmitter release. Nature 366:344-347.

Centonze D, Bracci E, Pisani A, Gubellini P, Bernardi G, Calabresi P (2002) Activation of dopamine $\mathrm{D}_{1}$-like receptors excites LTS interneurons of the striatum. Eur J Neurosci 15:2049-2052.

Centonze D, Grande C, Usiello A, Gubellini P, Erbs E, Martin AB, Pisani A, Tognazzi N, Bernardi G, Moratalla R, Borrelli E, Calabresi P (2003) Receptor subtypes involved in the presynaptic and postsynaptic actions of dopamine on striatal interneurons. J Neurosci 23:6245-6254.

Cooper AJ, Stanford IM (2001) Dopamine $\mathrm{D}_{2}$ receptor mediated presynaptic inhibition of striatopallidal GABA(A) IPSCs in vitro. Neuropharmacology 41:62-71.

Czubayko U, Plenz D (2002) Fast synaptic transmission between striatal spiny projection neurons. Proc Natl Acad Sci USA 99:15764-15769.

Delgado A, Sierra A, Querejeta E, Valdiosera RF, Aceves J (2000) Inhibitory control of the GABAergic transmission in the rat neostriatum by $\mathrm{D}_{2}$ dopamine receptors. Neuroscience 95:1043-1048.

Dunwiddie TV, Haas HL (1985) Adenosine increases synaptic facilitation in the in vitro rat hippocampus: evidence for a presynaptic site of action. J Physiol (Lond) 369:365-377.

Farries MA, Perkel DJ (2000) Electrophysiological properties of avian basal ganglia neurons recorded in vitro. J Neurophysiol 84:2502-2513.

Fitzpatrick JS, Akopian G, Walsh JP (2001) Short-term plasticity at inhibitory synapses in rat striatum and its effects on striatal output. J Neurophysiol 85:2088-2099.

Floran B, Aceves J, Sierra A, Martinez-Fong D (1990) Activation of $\mathrm{D}_{1}$ dopamine receptors stimulates the release of GABA in the basal ganglia of the rat. Neurosci Lett 116:136-140.

Floran B, Floran L, Sierra A, Aceves J (1997) $\mathrm{D}_{2}$ receptor-mediated inhibition of GABA release by endogenous dopamine in the rat globus pallidus. Neurosci Lett 237:1-4.

Flores-Hernández J, Galarraga E, Pineda JC, Bargas J (1994) Patterns of extrinsic and intrinsic synaptic transmission in the rat neostriatum as revealed by 4-aminopyridine. J Neurophysiol 72:2246-2256.

Flores-Hernández J, Hernandez S, Snyder GL, Yan Z, Fienberg AA, Moss SJ, Greengard P, Surmeier DJ (2000) $D_{1}$ dopamine receptor activation reduces $\mathrm{GABA}_{\mathrm{A}}$ receptor currents in neostriatal neurons through a PKA/ DARPP-32/PP1 signaling cascade. J Neurophysiol 83:2996-3004.

Galarraga E, Pacheco-Cano MT, Flores-Hernández JV, Bargas J (1994) Subthreshold rectification in neostriatal spiny projection neurons. Exp Brain Res 100:239-249.

Gao WJ, Wang Y, Goldman-Rakic PS (2003) Dopamine modulation of 
perisomatic and peridendritic inhibition in prefrontal cortex. J Neurosci 23:1622-1630.

Gerdeman GL, Ronesi J, Lovinger DM (2002) Postsynaptic endocannabinoid release is critical to long-term depression in the striatum. Nat Neurosci 5:446-451.

Gerfen CR (2000) Dopamine-mediated gene regulation in models of Parkinson's disease. Ann Neurol 47:S42-S50.

Gerfen CR, Young III WS (1988) Distribution of striatonigral and striatopallidal peptidergic neurons in both patch and matrix compartments: an in situ hybridization histochemistry and fluorescent retrograde tracing study. Brain Res 460:161-167.

Gerfen CR, Engber TM, Mahan LC, Susel Z, Chase TN, Monsma Jr FJ, Sibley DR (1990) $\mathrm{D}_{1}$ and $\mathrm{D}_{2}$ dopamine receptor-regulated gene expression of striatonigral and striatopallidal neurons. Science 250:1429-1432.

Groves PM (1983) A theory of the functional organization of the neostriatum and the neostriatal control of movement. Brain Res 286:109-132.

Guzman JN, Hernandez A, Galarraga E, Laville E, Vergara R, Erlij P, Valdiosera R, Aceves J, Bargas J (2002) Differential presynaptic modulation of inhibitory inputs to neostriatal projection neurons: dopamine modulates inputs from spiny axon collaterals but not from interneurons. Soc Neurosci Abstr 28:164.13.

Hanse E, Gustafsson B (2001) Quantal variability at glutamatergic synapses in area CAl of the rat neonatal hippocampus. J Physiol (Lond) 531:467-480.

Hernandez-Lopez S, Bargas J, Surmeier DJ, Reyes A, Galarraga E (1997) $D_{1}$ receptor activation enhances evoked discharge in neostriatal medium spiny neurons by modulating an L-type $\mathrm{Ca}^{2+}$ conductance. J Neurosci 17:3334-3342.

Hernandez-Lopez S, Tkatch T, Perez-Garci E, Galarraga E, Bargas J, Hamm $\mathrm{H}$, Surmeier DJ (2000) $\mathrm{D}_{2}$ dopamine receptors in striatal medium spiny neurons reduce L-type $\mathrm{Ca}^{2+}$ currents and excitability via a novel PLC $\beta_{1}$ $\mathrm{IP}_{3}$-calcineurin-signaling cascade. J Neurosci 20:8987-8995.

Ingham CA, Hood SH, Taggart P, Arbuthnott GW (1998) Plasticity of synapses in the rat neostriatum after unilateral lesion of the nigrostriatal dopaminergic pathway. J Neurosci 18:4732-4743.

Jaeger D, Kita H, Wilson CJ (1994) Surround inhibition among projection neurons is weak or nonexistent in the rat neostriatum. J Neurophysiol 72:2555-2558.

Kamiya H, Zucker RS (1994) Residual $\mathrm{Ca}^{2+}$ and short-term synaptic plasticity. Nature 371:603-606.

Katayama Y, Miyazaki S, Tsubokawa T (1981) Electrophysiological evidence favoring intracaudate axon collaterals of GABAergic caudate output neurons in the cat. Brain Res 216:180-186.

Kawaguchi Y, Wilson CJ, Emson PC (1990) Projection subtypes of rat neostriatal matrix cells revealed by intracellular injection of biocytin. J Neurosci 10:3421-3438.

Kawaguchi Y, Wilson CJ, Augood SJ, Emson PC (1995) Striatal interneurones: chemical, physiological and morphological characterization. Trends Neurosci 18:527-535.

Kincaid AE, Zheng T, Wilson CJ (1998) Connectivity and convergence of single corticostriatal axons. J Neurosci 18:4722-4731.

Kita H (1993) GABAergic circuits of the striatum. Prog Brain Res 99:51-72.

Kita H, Kita T (2001) Number, origins, and chemical types of rat pallidostriatal projection neurons. J Comp Neurol 437:438-448.

Koos T, Tepper JM (1999) Inhibitory control of neostriatal projection neurons by GABAergic interneurons. Nat Neurosci 2:467-472.

Koos T, Tepper JM, Goldman-Rakic P, Wilson CJ (2002) Electrophysiological properties and dopaminergic modulation of GABAergic inhibition among neostriatal projection neurons. Soc Neurosci Abstr 28:764.17.

Kubota Y, Kawaguchi Y (2000) Dependence of GABAergic synaptic areas on the interneuron type and target size. J Neurosci 20:375-386.

Kuo H, Chang HT (1992) Ventral pallido-striatal pathway in the rat brain: a light and electron microscopic study. J Comp Neurol 321:626-636.

Lenz S, Perney TM, Qin Y, Robbins E, Chesselet MF (1994) GABA-ergic interneurons of the striatum express the Shaw-like potassium channel Kv3.1. Synapse 18:55-66.

Mengual E, Pickel VM (2002) Ultrastructural immunocytochemical local- ization of the dopamine $\mathrm{D}_{2}$ receptor and tyrosine hydroxylase in the rat ventral pallidum. Synapse 43:151-162.

Mermelstein PG, Song WJ, Tkatch T, Yan Z, Surmeier DJ (1998) Inwardly rectifying potassium (IRK) currents are correlated with IRK subunit expression in rat nucleus accumbens medium spiny neurons. J Neurosci 18:6650-6661.

Momiyama T, Koga E (2001) Dopamine $\mathrm{D}_{2}$-like receptors selectively block $\mathrm{N}$-type $\mathrm{Ca}^{2+}$ channels to reduce GABA release onto rat striatal cholinergic interneurones. J Physiol (Lond) 533:479-492.

Nisenbaum ES, Wilson CJ (1995) Potassium currents responsible for inward and outward rectification in rat neostriatal spiny projection neurons. J Neurosci 15:4449-4463.

Oorschot DE (1996) Total number of neurons in the neostriatal, pallidal, subthalamic, and substantia nigral nuclei of the rat basal ganglia: a stereological study using the Cavalieri and optical disector methods. J Comp Neurol 366:580-599.

Pacheco-Cano MT, Bargas J, Hernandez-Lopez S, Tapia D, Galarraga E (1996) Inhibitory action of dopamine involves a subthreshold $\mathrm{Cs}^{+}$sensitive conductance in neostriatal neurons. Exp Brain Res 110:205-211.

Park MR, Lighthall JW, Kitai ST (1980) Recurrent inhibition in the rat neostriatum. Brain Res 194:359-369.

Paxinos G, Watson C (1982) The rat brain in stereotaxic coordinates. New York: Academic.

Pisani A, Bonsi P, Centonze D, Calabresi P, Bernardi G (2000) Activation of $\mathrm{D}_{2}$-like dopamine receptors reduces synaptic inputs to striatal cholinergic interneurons. J Neurosci 20:RC69(1-6).

Radnikow G, Misgeld U (1998) Dopamine $D_{1}$ receptors facilitate $G_{A B A}$ synaptic currents in the rat substantia nigra pars reticulata. J Neurosci 18:2009-2016.

Rajakumar N, Elisevich K, Flumerfelt BA (1994) The pallidostriatal projection in the rat: a recurrent inhibitory loop? Brain Res 651:332-336.

Rebec GV, Curtis SD (1988) Reciprocal zones of excitation and inhibition in the neostriatum. Synapse 2:633-635.

Redgrave P, Prescott TJ, Gurney K (1999) The basal ganglia: a vertebrate solution to the selection problem? Neuroscience 89:1009-1023.

Roberts RC, Force M, Kung L (2002) Dopaminergic synapses in the matrix of the ventrolateral striatum after chronic haloperidol treatment. Synapse 45:78-85.

Somogyi P, Bolam JP, Smith AD (1981) Monosynaptic cortical input and local axon collaterals of identified striatonigral neurons. A light and electron microscopic study using the Golgi-peroxidase transportdegeneration procedure. J Comp Neurol 195:567-584.

Stern EA, Jaeger D, Wilson CJ (1998) Membrane potential synchrony of simultaneously recorded striatal spiny neurons in vivo. Nature 394:475-478.

Surmeier DJ, Reiner A, Levine MS, Ariano MA (1993) Are neostriatal dopamine receptors co-localized? Trends Neurosci 16:299-305.

Tunstall MJ, Oorschot DE, Kean A, Wickens JR (2002) Inhibitory interactions between spiny projection neurons in the rat striatum. J Neurophysiol 88:1263-1269.

Wickens JR (1993) A theory of the striatum. New York: Pergamon.

Wickens JR, Oorshcot DE (2000) Neuronal dynamics and surround inhibition in the neostriatum: a possible connection. In: Brain dynamics and the striatal complex. (Miller R, Wickens JR, eds), pp 141-150. Sydney: Harwood Academic.

Wilson CJ, Groves PM (1980) Fine structure and synaptic connections of the common spiny neuron of the rat neostriatum: a study employing intracellular injections of horseradish peroxidase. J Comp Neurol 194:599-615.

Yasumoto S, Tanaka E, Hattori G, Maeda H, Higashi H (2002) Direct and indirect actions of dopamine on the membrane potential in medium spiny neurons of the mouse neostriatum. J Neurophysiol 87:1234-1243.

Yung KK, Smith AD, Levey AI, Bolam JP (1996) Synaptic connections between spiny neurons of the direct and indirect pathways in the neostriatum of the rat: evidence from dopamine receptor and neuropeptide immunostaining. Eur J Neurosci 8:861-869.

Zucker RS (1999) Calcium- and activity-dependent synaptic plasticity. Curr Opin Neurobiol 9:305-313. 